\title{
Stability of Optical Elements in the NIF Target Area Building
}

\author{
David J. Trummer \\ Richard J. Foley \\ Gene S. Shaw
}

This paper was prepared for submittal to the

3rd Annual International Conference on Solid State Lasers for Application to Inertial Confinement Fusion (ICF)

Monterey, CA

June 7-12, 1998

August 1998

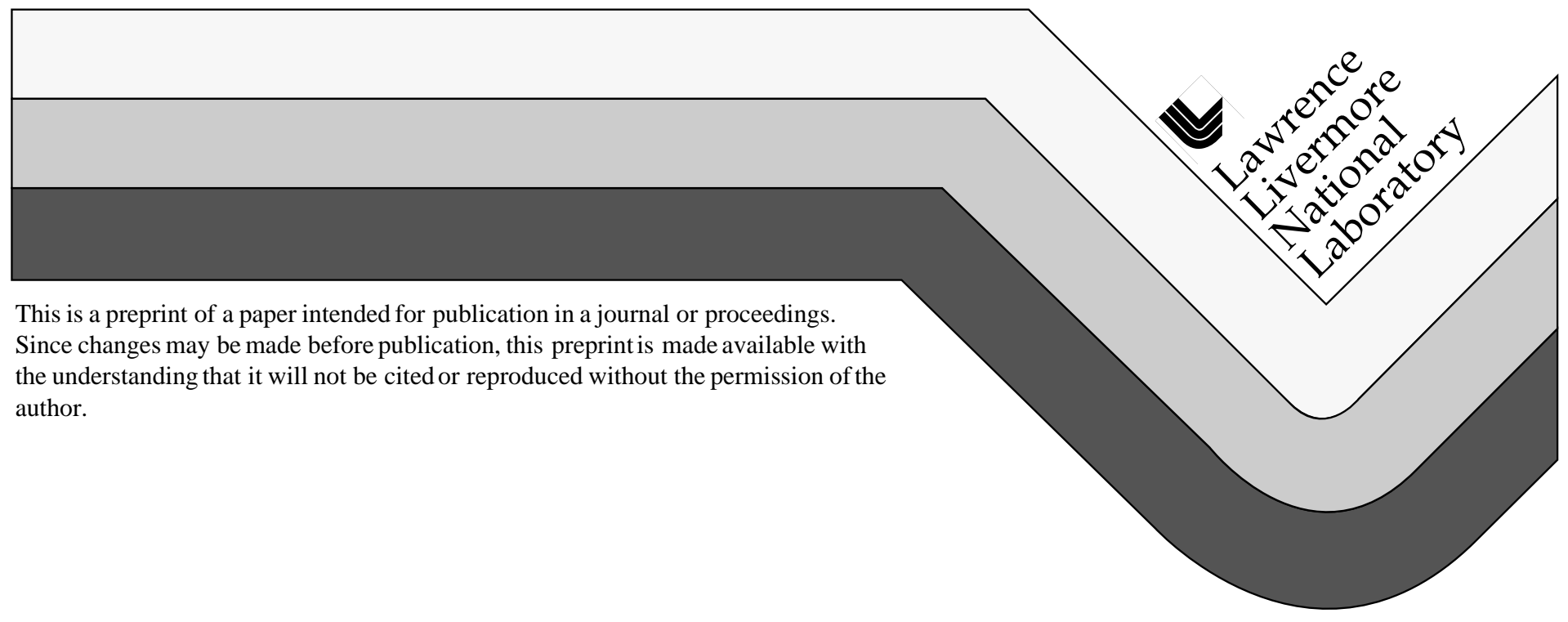




\section{DISCLAIMER}

This document was prepared as an account of work sponsored by an agency of the United States Government. Neither the United States Government nor the University of California nor any of their employees, makes any warranty, express or implied, or assumes any legal liability or responsibility for the accuracy, completeness, or usefulness of any information, apparatus, product, or process

disclosed, or represents that its use would not infringe privately owned rights. Reference herein to any specific commercial product, process, or service by trade name, trademark, manufacturer, or otherwise, does not necessarily constitute or imply its endorsement, recommendation, or favoring by the United States Government or the University of California. The views and opinions of authors expressed herein do not necessarily state or reflect those of the United States Government or the University of California, and shall not be used for advertising or product endorsement purposes. 


\title{
Stability of Optical Elements in the NIF Target Area Building
}

\author{
David J. Trummer \\ Richard J. Foley \\ Gene S. Shaw \\ Lawrence Livermore National Laboratory \\ Livermore, California 94550 USA
}

\begin{abstract}
The Target Area Building (TAB) of the National Ignition Facility (NIF) is 300 feet long, 100 feet wide, and 100 feet tall and is comprised of a cylindrical target building and two switchyard space frames. The reinforced concrete target building houses the target chamber, target positioner, turning mirrors, final optics assemblies, and diagnostics, while the steel switchyard space frames support turning mirrors and diagnostic equipment. Within the TAB, the 192 independent laser beams of the NIF laser system are required to be accurately positioned. In order to satisfy the engineering system requirement for optical system positioning (stability on target), the TAB must provide a stable platform for optical elements before and during a shot. This paper summarizes the stability analyses that were performed in support of the TAB and optical system design.

Sources that influence optic stability are structural excitations, such as ambient and wind induced vibrations, and thermal transients, such as diurnal and HVAC temperature changes. A positioning error budget has been developed for the NIF project for use in the design and evaluation of structures which support optical elements. To satisfy the error budget requirements, vibrational stability will be achieved through a combination of facility design, optic support structure design, and passive damping. Thermal stability will be accomplished by using high thermal-mass concrete structures, conditioned air flow, and a reduction of heat sources.

Finite element analysis has been used to evaluate the design of the TAB and optical support structures. A detailed structural model of the TAB that includes the target positioner, target chamber, turning mirrors, and diagnostics, has been used for stability evaluations. Finite element analyses covering ambient ground vibration, thermal loads, pressure fluctuations, and wind excitations have demonstrated that the current design of the TAB provides a stable platform for maintaining beam alignment.
\end{abstract}

Keywords: NIF, optics, mirrors, stability, ambient vibration, finite elements, laser

\section{INTRODUCTION}

The National Ignition Facility is a high-power laser facility used for research in Inertial Confinement Fusion. The NIF laser system, shown in Figure 1, consists of 192 laser beams that are required to be positioned on target with a very high degree of accuracy. In order to satisfy the engineering system requirements for optical system positioning (stability on target), the facility must provide a stable platform to maintain beam alignment in the laser bay, switchyard, and target area.

The beam position on target is dependent on the accuracy of the alignment process and the stability of the laser system before and during a shot. It is during the approximately one hour alignment procedure prior to a shot, and during the shot that the facility must provide vibrational and thermal stability for optical components, diagnostics, the target chamber, and the target positioner.

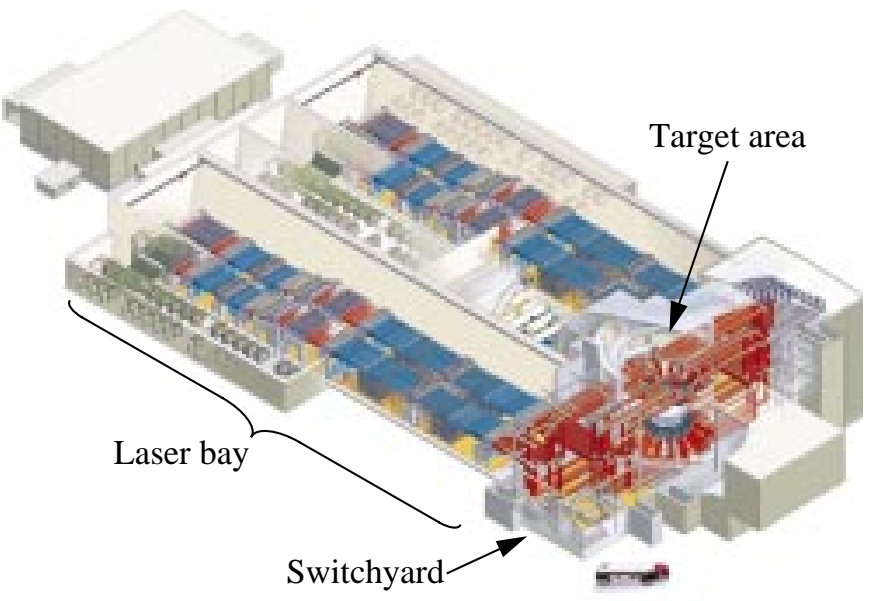

Figure 1. The National Ignition Facility. 
Finite element analysis has been used as a guide in the design of the combined conventional facility and the optical system structures. The analytical calculations have incorporated the concrete foundation, walls, and floors, and mirror frames and their support structures. Soil-structure interaction, ambient vibration, thermal, wind, building differential pressure, and seismic loads have been analyzed. In this paper, the results of the analyses used to demonstrate that the design of the target area building provides a stable platform for maintaining beam alignment will be presented.

\section{STABILITY REQUIREMENTS}

To assure that each laser beam is successfully positioned on target, a positioning error stability budget has been developed for the mechanical design and evaluation of equipment and structures that support large aperture optical elements. ${ }^{1}$ The stability budget is used for evaluating the performance of NIF structures when they are subjected to conditions which can cause a change (drift) in the position of optical elements from an aligned position during the alignment procedures before a shot. Conditions that can cause drift include ambient vibration input, wind fluctuations, thermal variations, acoustical input, and HVAC pressure fluctuations. The stability allocation for the structural response due to different input loads is specified as follows:

$$
\Delta_{\text {Drift }}=\Delta_{\text {Structural }}+\Delta_{\text {Thermal Transient }}+\Delta_{\text {Contingency }}
$$

where $\Delta_{\text {Drift }}$ is the total budget for drift of the superstructure, mirror frames, and their support structures. The structural and thermal portions of the allocation are divided further:

$$
\begin{gathered}
\left(\Delta_{\text {Structural }}\right)^{2}=\left(\beta * \Delta_{\text {Broadband Ambient Vibration }}\right)^{2}+\left(\Delta_{\text {Local Vibration Sources }}\right)^{2}+\left(\Delta_{\text {Broadband Acoustic Vibrations }}\right)^{2} \\
+\left(\Delta_{\text {Target Building / Switchyards Acoustic Vibrations }}\right)^{2}+\left(\Delta_{\text {Target Building / Switchyards Wind Vibrations }}\right)^{2} \\
+\left(\Delta_{\text {Target Building / Switchyards HVAC Pressure Fluctuations }}\right)^{2}+\left(\Delta_{\text {Gas Environment Pressure Fluctuations }}\right)^{2} \\
\Delta_{\text {Thermal Transient }}=\Delta_{\text {Diurnal Transient Temperature Changes }}+\Delta_{\text {Internal HVAC Transient Temperature Changes }} \\
+\Delta_{\text {Local Transient Temperature Changes }}
\end{gathered}
$$

where $\beta$ is a factor to account for foundation flexibility in fixed base analyses. Because the structural excitations are assumed to occur randomly, the Square Root Sum of the Squares (SRSS) method is used to combine the structural components.

To achieve the beam position on target, the NIF system requirement specifies that "the rms deviation in the position of the centroids of all beams from their specified aiming points shall not exceed 50 micrometers $(\mu \mathrm{m})$ at the target plane or its equivalent." Because each component along a beam line can cause the laser to drift from its aligned position, the stability budget allocates a certain portion of the total allocation to each optic in the beam path. The total drift for TAB optics is 0.68 microradians $(\mu \mathrm{rad})$ for rotation and 6.8 microns $(\mu \mathrm{m})$ for translation. The breakdown of the total drift for the large aperture optics is provided in Tables 1,2, and 3.

Table 1. Stability allocations for large aperture optical elements.

\begin{tabular}{ccc}
\hline Input Excitation & $\begin{array}{c}\text { Rotation } \\
(\mu \mathrm{rad})\end{array}$ & $\begin{array}{c}\text { Translation } \\
(\mu \mathrm{m})\end{array}$ \\
\hline$\Delta_{\text {Structural }}$ & 0.41 & 4.1 \\
$\Delta_{\text {Thermal Transient }}$ & 0.24 & 2.4 \\
$\Delta_{\text {Contingency }}$ & 0.03 & 0.3 \\
\hline Stability Limit & 0.68 & 6.8 \\
\hline
\end{tabular}


Table 2. Structural allocations for large aperture optical elements.

\begin{tabular}{ccc}
\hline Structural Excitation & $\begin{array}{c}\text { Rotation } \\
(\mu \mathrm{rad})\end{array}$ & $\begin{array}{c}\text { Translation } \\
(\mu \mathrm{m})\end{array}$ \\
\hline$\Delta_{\text {Ambient Vibration }}$ & $0.32^{\mathrm{a}}$ & $3.2^{\mathrm{b}}$ \\
$\Delta_{\text {Local Vibration Sources }}$ & 0.10 & 1.0 \\
$\Delta_{\text {Broadband Acoustic Vibrations }}$ & 0.10 & 1.0 \\
$\Delta_{\text {Target Building / Switchyards Acoustic Vibrations }}$ & 0.15 & 1.5 \\
$\Delta_{\text {Target Building / Switchyards Wind Vibrations }}$ & 0.15 & 1.5 \\
$\Delta_{\text {Target Building / Switchyards HVAC Pressure Fluctuations }}$ & 0.05 & 0.5 \\
$\Delta_{\text {Gas Environment Pressure Fluctuations }}$ & 0.05 & 0.5 \\
\hline SRSS Total & 0.41 & 4.1 \\
\hline
\end{tabular}

a. The $0.32 \mu \mathrm{rad}$ ambient vibration allocation becomes $0.20 \mu \mathrm{rad}$ when soil-structure interaction is accounted for (reduction factor $\beta=1.6$ for rotations)

b. The $3.2 \mu \mathrm{m}$ ambient vibration allocation becomes $2.7 \mu \mathrm{m}$ when soil-structure interaction is accounted for (reduction factor $\beta=1.2$ for translations)

Table 3. Thermal transient allocations for large aperture optical elements.

\begin{tabular}{ccc}
\hline Thermal Excitation & $\begin{array}{c}\text { Rotation } \\
(\mu \mathrm{rad})\end{array}$ & $\begin{array}{c}\text { Translation } \\
(\mu \mathrm{m})\end{array}$ \\
\hline$\Delta_{\text {Diurnal Transient Temperature Changes }}$ & 0.08 & 0.8 \\
$\Delta_{\text {Internal HVAC Transient Temperature Changes }}$ & 0.13 & 1.3 \\
$\Delta_{\text {Local Transient Temperature Changes }}$ & 0.02 & 0.2 \\
\hline Total & 0.24 & 2.4 \\
\hline
\end{tabular}

\section{FINITE ELEMENT MODELS}

The finite element (FE) model of the TAB is shown in Figure 2. The TAB is comprised of the target building, two switchyard buildings, and two switchyard space frames. The switchyard space frames support turning mirrors and diagnostic equipment on a steel frame, while the target building houses turning mirrors, final optics assemblies, the target chamber, the target positioner, and diagnostics. In the finite element model, the foundation is assumed to be rigid, therefore no flexibility of the foundation is included in the analysis. Separate soilstructure-interaction (SSI) analyses were performed to determine the affect of foundation flexibility on the rotations and displacements of optics. ${ }^{2}$ Based on

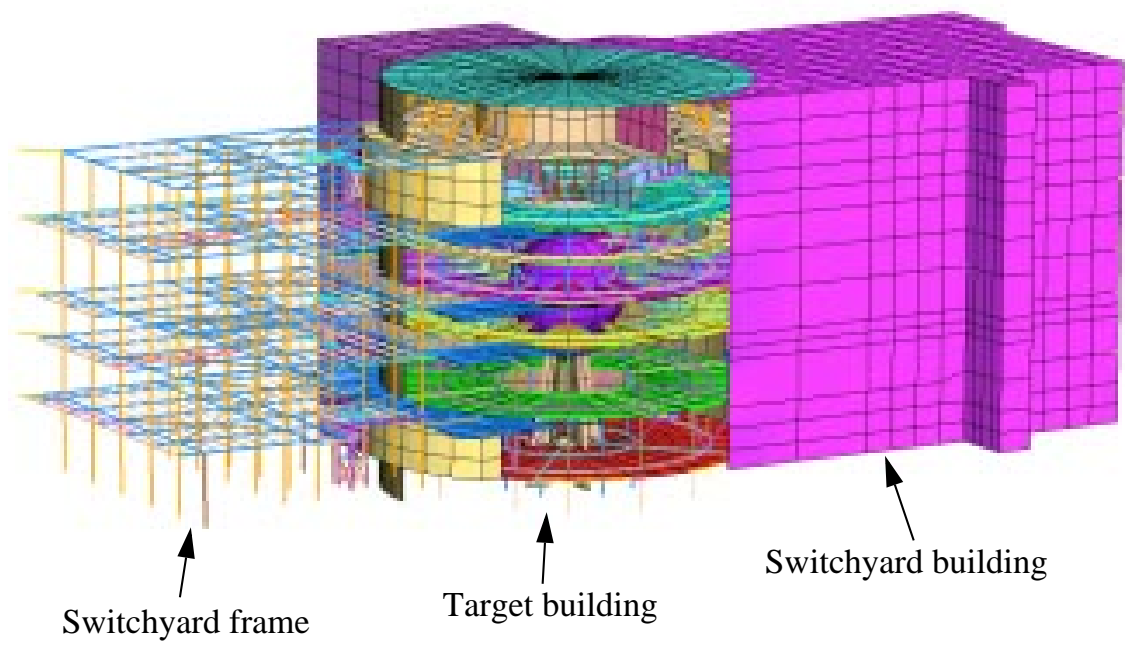

Figure 2. Finite element model of the target area building. 
comparisons between SSI and fixed base analysis results, a reduction factor $(\beta)$ was introduced into the ambient vibration portion of the structural allocation to account for foundation flexibility in fixed base analyses.

The switchyard steel frame is supported laterally by the switchyard and target building concrete walls to maximize the stability of the supported optics. Connections are made only at the corners of switchyard walls to avoid the low frequency panel modes that occur away from the corners. The connections are shown in Figure 3.
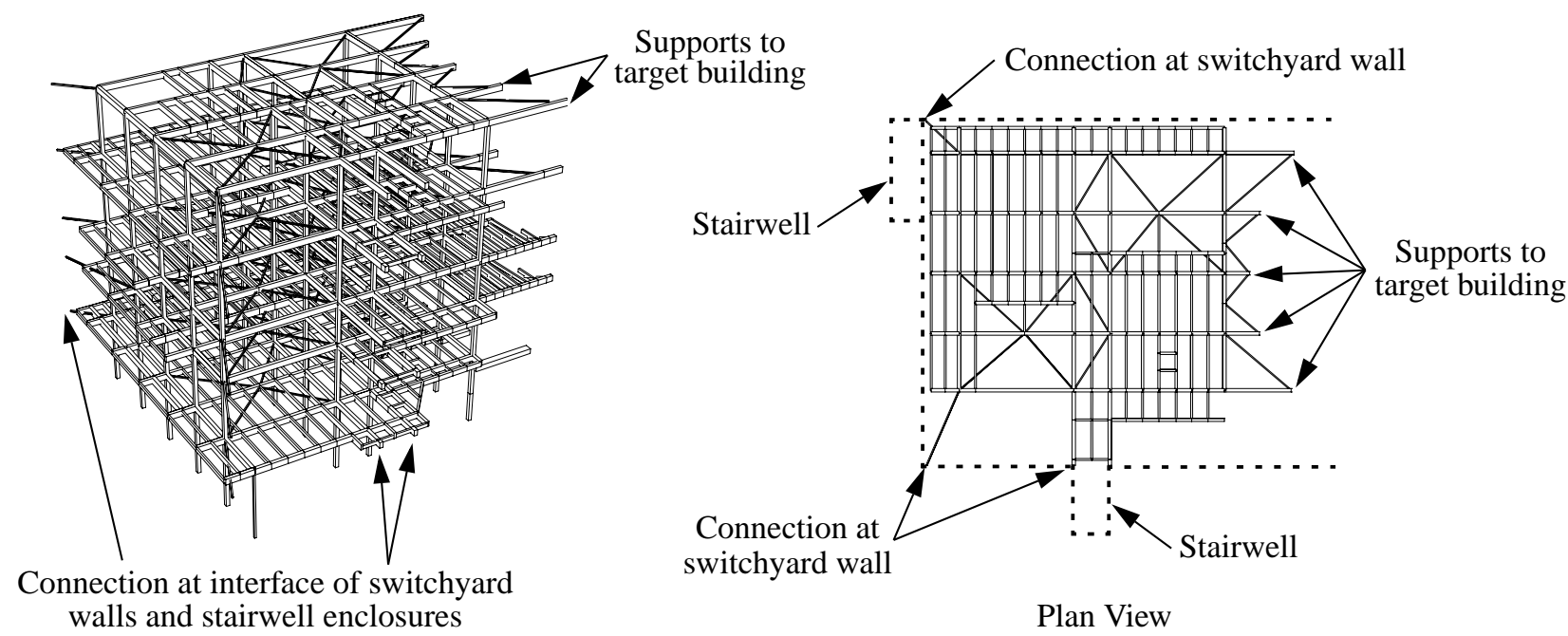

walls and stairwell enclosures

Plan View

Figure 3. Connections of the switchyard steel frame to the concrete walls.

Since the ambient vibration criteria is based on rotations and displacements of the optical components using input motion at the top of the foundation, detailed FE models of subsystems were included in the global FE model of the TAB. Switchyard subsystems include LM4 and LM5 mirror frames and their support structures, and diagnostic equipment. Target area subsystems include LM6-LM8 mirror frames and their support structures, the target positioner, final optics assemblies, and diagnostic equipment. Figure 4 shows the FE models of switchyard LM4 and LM5 mirror frames.
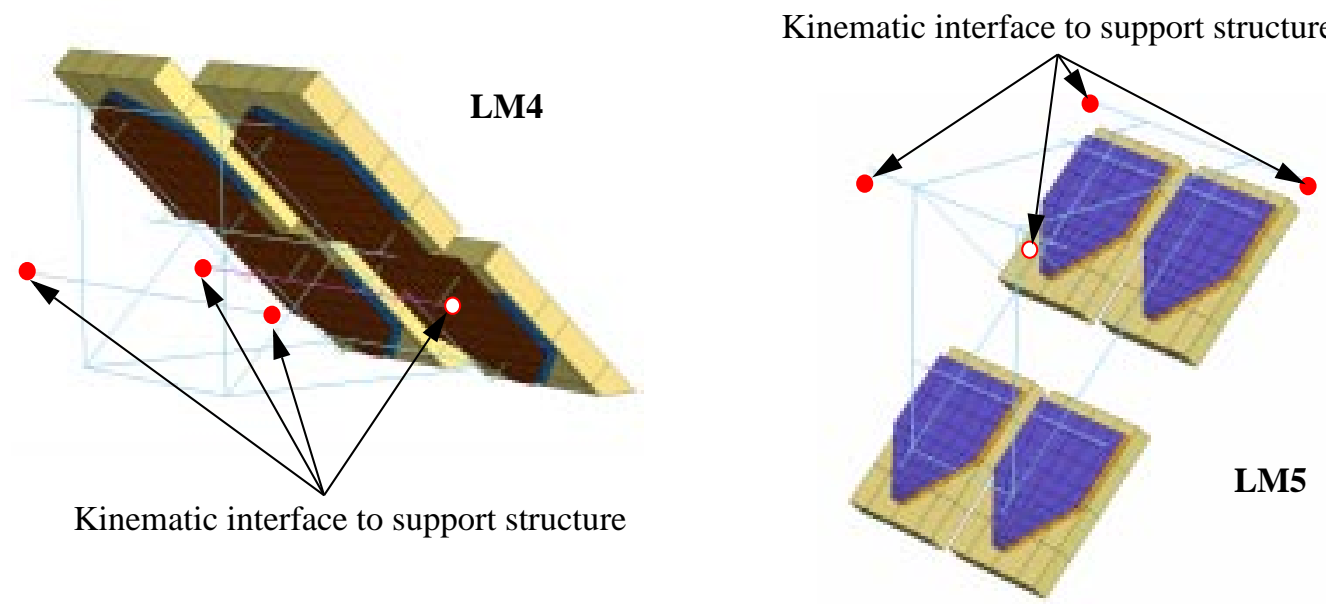

Figure 4. Switchyard LM4 and LM5 mirror frames.

The mirror frames are kinematically mounted in support structures that position the frames in the appropriate location. For ambient vibration calculations, the input motion is sufficiently small that the kinematic mounts are assumed to behave as if pinned (no translation across the interface, but free to rotate). Large subframes (two per switchyard) are used to support the LM4 mirror frames as shown in Figure 5 (only one subframe is included in the FE model). Several LM5s were also included in the FE model for evaluation, each having a unique support frame design because of space limitations (see Figure 5). 


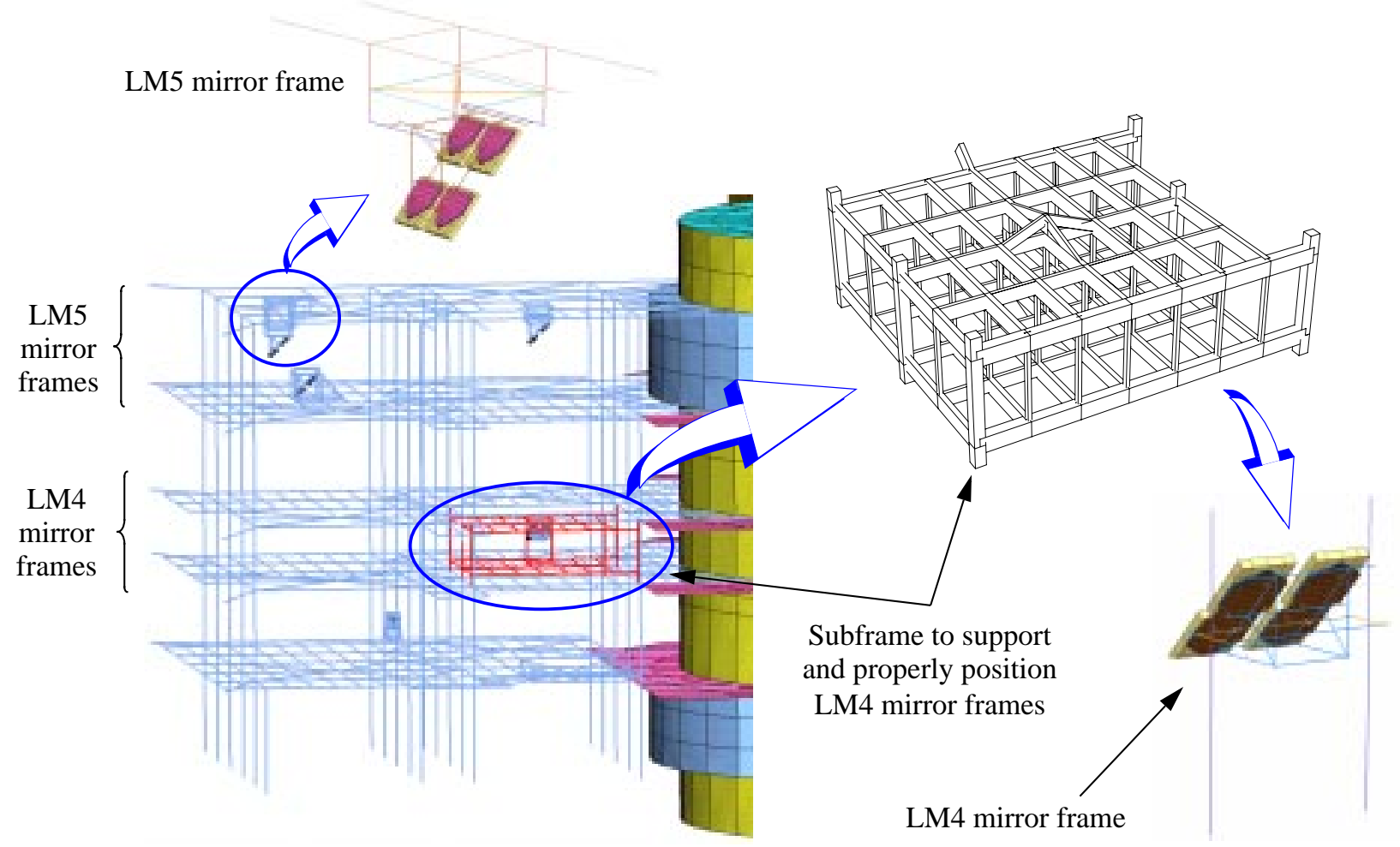

Figure 5. Switchyard showing LM4 and LM5 mirror frames and their support structures.

The target area optical elements included in the FE model are shown in Figure 6. In order to provide stable floors in the target building for optics and diagnostics, concrete columns, floor ribbing, and steel supports and trusses are used. The concrete columns span from the foundation to the roof while providing space for operations and maintenance. The target chamber, support pedestal, and lateral restraints to the target building floors are shown in Figure 7. Figure 8 shows the model of a typical target building mirror frame that supports LM7 and LM8 turning mirrors. Figure 9 shows the model of the target positioner (supported by the diagnostics floor). The TAB FE model was also used to assess the effects of diurnal thermal loads, HVAC pressure fluctuations, and wind loads on optical stability.

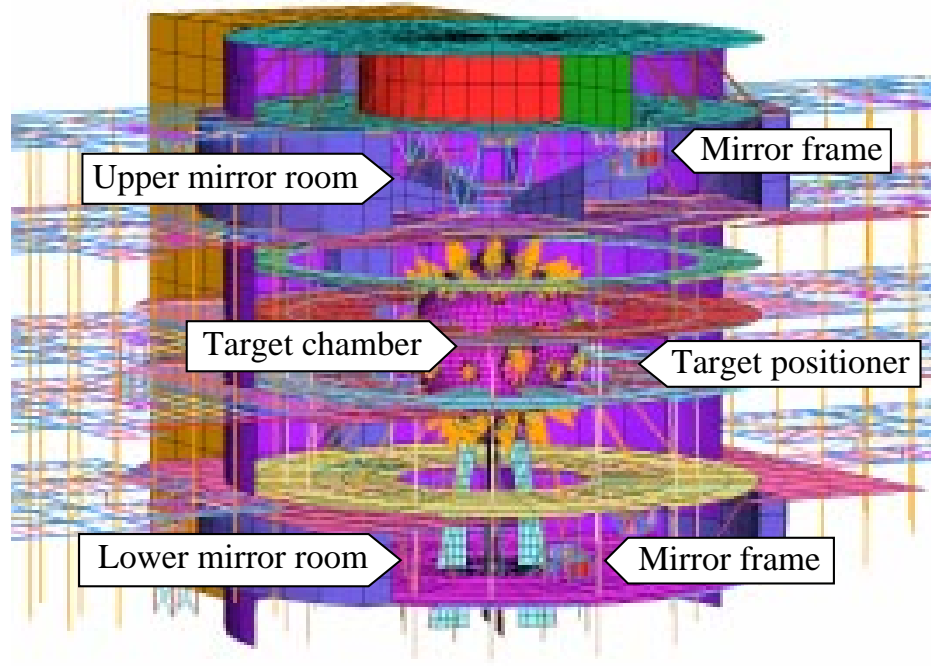

Figure 6. The target area FE model includes turning mirrors, the target positioner, and the target chamber.

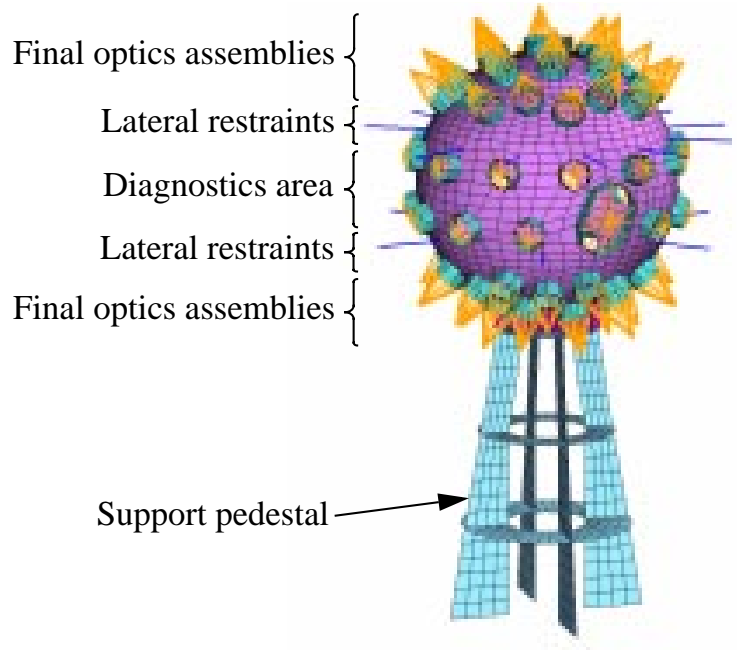

Figure 7. Finite element model of the target chamber showing lateral restraints to the target building floors. 
The GEMINI finite element $\operatorname{code}^{3}$ was used to calculate mode shapes, thermal response and steady state wind loads. GEMPSD $^{4}$ was used to calculate the response to ambient vibration input using the GEMINI generated output.

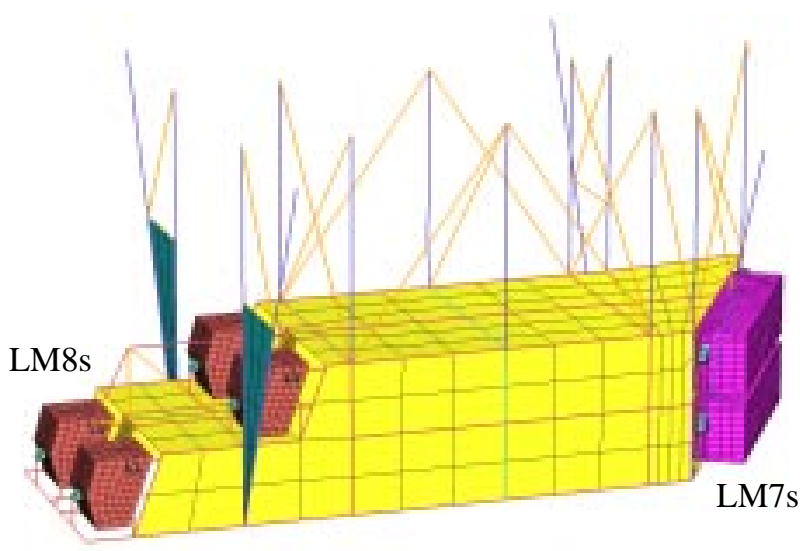

Figure 8. Target building mirror frame finite element model with LM7 and LM8 turning mirrors.

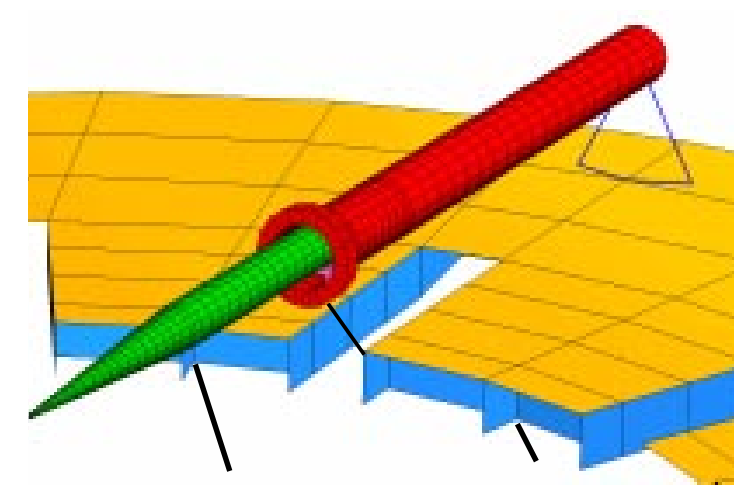

Figure 9. Finite element model of the target positioner supported by the diagnostics floor.

\section{RESULTS}

The lowest frequencies of the TAB occur in the 4 to $6 \mathrm{hz}$ range, characterized by bending of the switchyard walls and roof (Figure 10). To avoid these low frequency "breathing" modes, the switchyard frame is laterally supported to the switchyard building only at wall intersections (see Figure 3). The fundamental lateral mode of the TAB is in the Z-direction and occurs at $7.0 \mathrm{hz}$ as shown in Figure 10, while the second lateral mode is in the X-direction at $7.5 \mathrm{hz}$. These two lateral modes of the $\mathrm{TAB}$ influence all structures that are attached to the TAB, such as the switchyard steel frames and target bay floors and supported optical elements. The first mode of the target building floors is also at $7.0 \mathrm{~Hz}$, while the first mode of the target building roof occurs at $8.7 \mathrm{~Hz}$. Typically, the stability criteria is satisfied when substructures supported within the TAB have fundamental frequencies greater than $30 \mathrm{hz}$.

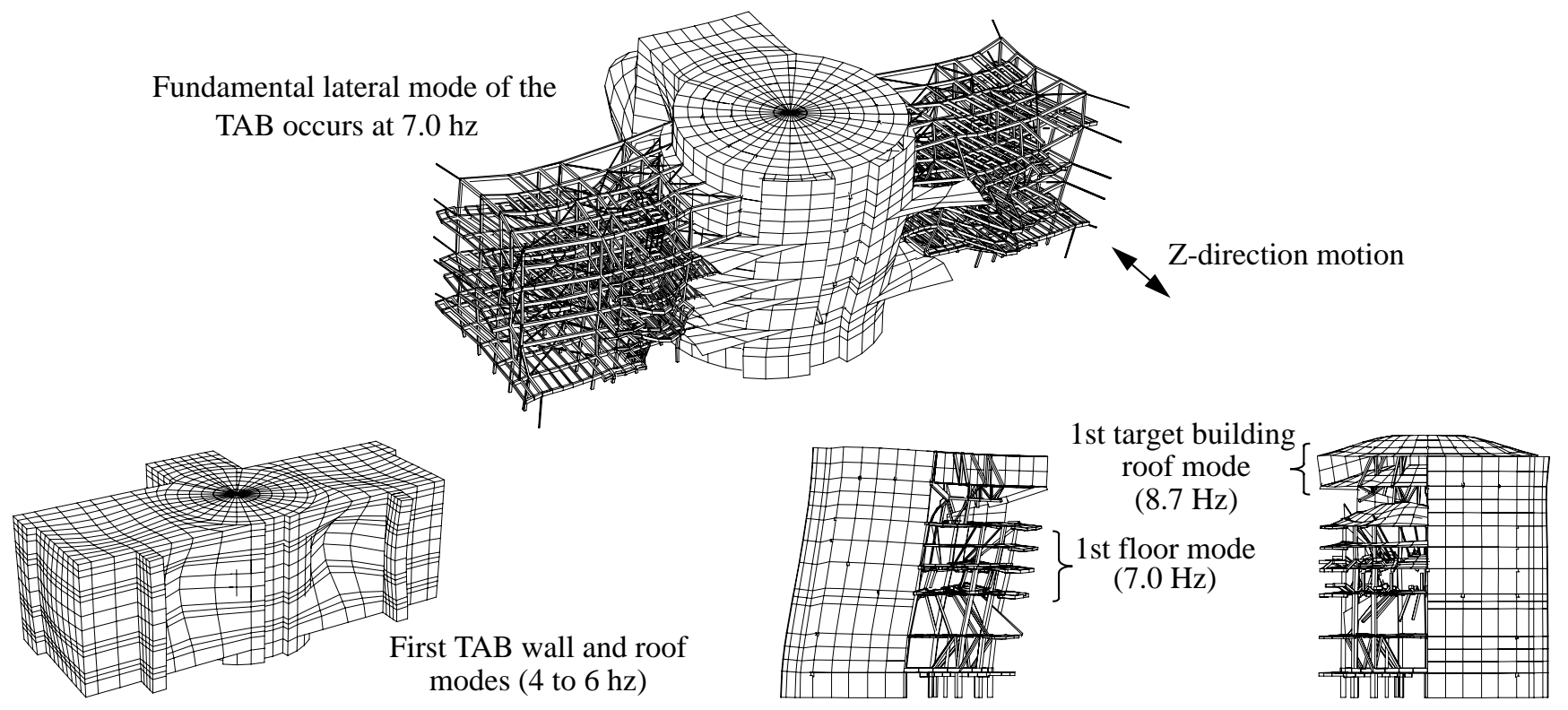

Figure 10. Various modes of the target area building. 


\subsection{Ambient Vibration Excitation}

The target area building will be subjected to low-level ambient vibrations from external sources such as wind and vehicle traffic. TAB optics and diagnostics must satisfy their positioning error stability allocation for the ambient vibration input motion that is specified as the broadband top-of-foundation PSD shown in Figure 11. For stability evaluations, design margins are defined as:

$$
\text { Design Margin }=\frac{\text { Stability Limit }}{\text { Calculated Value }}
$$

A design margin of one or greater is acceptable. Calculated mirror rotations are based on local coordinates, with the two in-plane rotations being combined in an SRSS fashion to compare to the criteria. The ambient vibration stability calculations were performed using composite modal damping. A damping value of $2.0 \%$ of critical damping was applied to all concrete components and a damping value of $0.5 \%$ of critical damping was applied to all other components. Analysis results are tabulated in Table 4 for TAB turning mirrors, the target positioner, and the final optics assemblies.

Table 4. Stability of TAB large aperture optics due to ambient vibration input.

\begin{tabular}{ccc}
\hline Component & Requirement & Minimum Design Margin \\
\hline Switchyard turning mirrors & $0.20 \mu \mathrm{rad}$ & 1.1 \\
Target building turning mirrors & $0.20 \mu \mathrm{rad}$ & 1.3 \\
Target positioner & $2.7 \mu \mathrm{m}$ & 1.0 \\
Final optics assemblies & $2.7 \mu \mathrm{m}$ & 1.7 \\
\hline
\end{tabular}

\subsection{Diurnal Temperature Loads}

To determine the effect of diurnal temperature loads on the performance of alignment critical components in the TAB, transient thermal and static thermal analyses were performed using the TAB FE model. The transient thermal analyses were used to determine the maximum temperature change that could occur in the TAB concrete walls and roof during the alignment process prior to a shot. In the transient analyses, a 0.91 meter ( $3 \mathrm{ft}$.) thick concrete slab with a 0.20 meter $(8 \mathrm{in}$.) layer of insulation on the exterior surface was used to represent the walls and roof. The results of the transient analyses were then used to scale the static results generated with the TAB FE model to the appropriate alignment time period.

The static analysis assumed the temperature load distribution shown in Figure 12 based on the transient analyses. Temperature loads were not applied at locations covered by soil and other structures. The predicted rotations from the static analysis were then scaled by the bulk temperature change of $0.063{ }^{\circ} \mathrm{C} /{ }^{\circ} \mathrm{C}\left(0.031{ }^{\circ} \mathrm{F} /{ }^{\circ} \mathrm{F}\right)$ (determined in the transient analyses) corresponding to a one hour alignment period. The scaled results are presented in Table 5. 


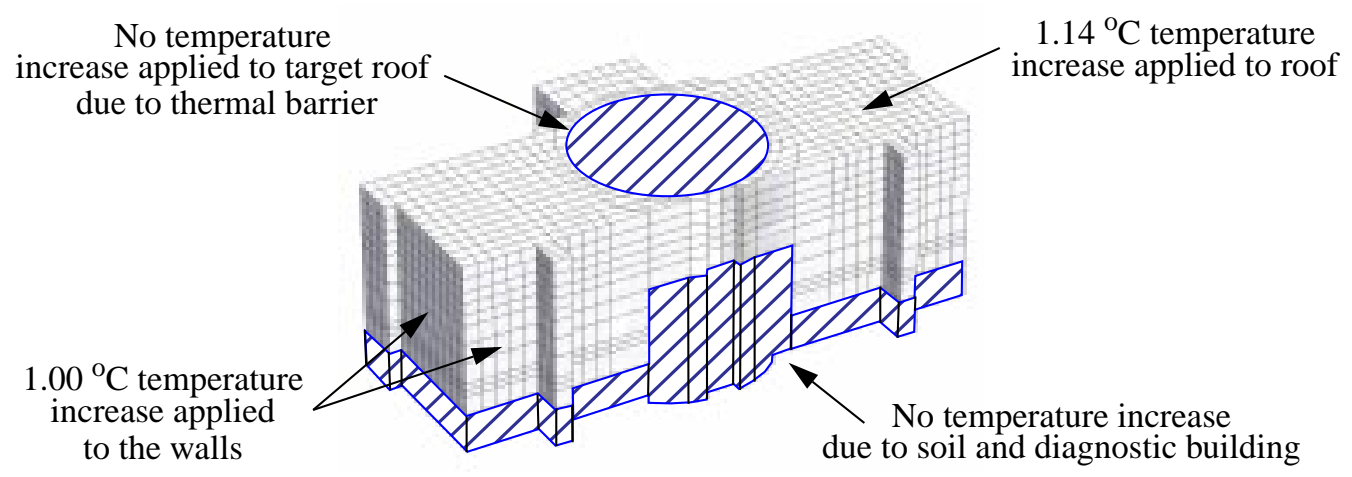

Figure 12. Load distribution for static thermal analysis due to diurnal temperature variations.

Table 5. Stability of TAB large aperture optics due to diurnal thermal loads.

\begin{tabular}{ccc}
\hline Component & Requirement & Minimum Design Margin \\
\hline Switchyard turning mirrors & $0.08 \mu \mathrm{rad}$ & 1.0 \\
Target building turning mirrors & $0.08 \mu \mathrm{rad}$ & 2.4 \\
Target positioner & $0.8 \mu \mathrm{m}$ & 1.3 \\
Final optics assemblies & $0.8 \mu \mathrm{m}$ & 5.8 \\
\hline
\end{tabular}

\subsection{Steady State Wind Loads}

The target building optical elements were also evaluated for performance due to wind loads. ${ }^{5}$ A design wind speed of 116 $\mathrm{km} / \mathrm{h}(72 \mathrm{mi} / \mathrm{h}$ ) was applied to the walls and roof of the target area building as static pressures (see Figure 13) with the dynamic effects of wind gusts and structural dynamics accounted for by a nonfrequency-dependent gust scale factor. The static analysis results, scaled to the appropriate wind speed developed for the Livermore site based on historical data, are presented in Table 6.

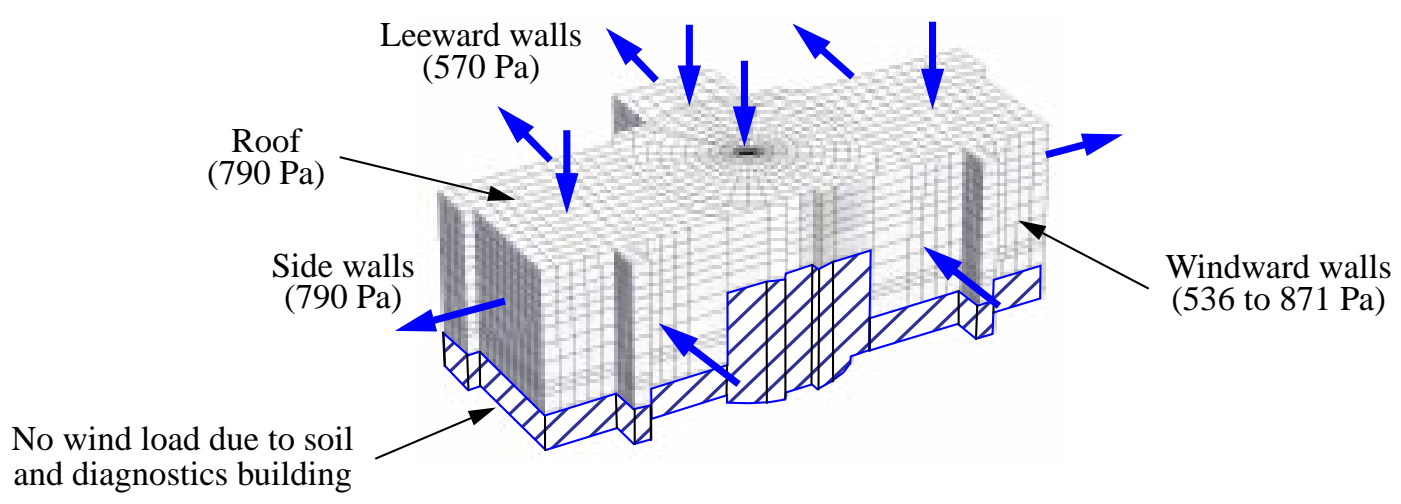

Figure 13. Design wind speed $(116 \mathrm{~km} / \mathrm{h})$ load distribution for static analysis due to steady state wind loads. 
Table 6. Stability of TAB large aperture optics due to external wind loads.

\begin{tabular}{ccc}
\hline Component & Requirement & Minimum Design Margin \\
\hline Switchyard turning mirrors & $0.15 \mu \mathrm{rad}$ & 4.4 \\
Target building turning mirrors & $0.15 \mu \mathrm{rad}$ & 1.3 \\
Target positioner & $1.5 \mu \mathrm{m}$ & 3.8 \\
Final optics assemblies & $1.5 \mu \mathrm{m}$ & 1.5 \\
\hline
\end{tabular}

\section{SUMMARY}

The target area building design was optimized to provide maximum stability for the mirror assemblies, target positioner, final optics assemblies, and diagnostics. Finite element analyses covering ambient ground vibration, thermal loads, and wind excitations have demonstrated that the current design of the TAB provides a stable platform for maintaining beam alignment.

\section{ACKNOWLEDGMENTS}

This work was performed at Lawrence Livermore National Laboratory under the auspices of the United States Department of Energy, Contract Number W-7405-ENG-48.

\section{REFERENCES}

1. S. Sommer, "Positioning Error (Stability on Target) Budget," NIF-0000148-OC, Lawrence Livermore National Laboratory, Livermore, CA, February 10, 1998.

2. M. Tabatabaie, "Analyses of Soil Structure Interaction Due To Ambient Vibration, Switchyard and Target Buildings, Proposed National Ignition Facility, Livermore, California," File No. 10-3005-08, Kleinfelder, Inc., Pleasanton, CA, March 16, 1998.

3. R. Murray, "GEMINI - A Computer Program for Two and Three Dimensional Linear Static, and Seismic Structural Analysis," Lawrence Livermore National Laboratory Report, Livermore, CA, UCRL-52823 (September 1985).

4. M. Gerhard, "GEMPSD - PSD Analysis," Lawrence Livermore National Laboratory, Livermore, CA, October 30, 1997.

5. S. Sommer, and D. Trummer, "Evaluation of Effects of Wind Loads on Switchyards and Target Building," NIF-0001591, Lawrence Livermore National Laboratory, Livermore, CA, February 27, 1997., and Trummer, D.J. 